3 Fakunle YM. Tropical splenomegaly. Part I. Tropical Africa. Clin Haematol 1981;10:963-75.

4 Voller A, Draper CC. Immunodiagnosis and seroepidemiology of malaria. Br Med Bull 1982;38:173-7.

${ }^{5}$ Deverill I. Kinetic measurements of the immunoprecipitin reaction using the centrifugal analyser. In: Price CP, Spencer K, eds. Centrifugal analysers in clinical chemistry. Eastbourne: Praeger, 1980.

(Accepted 1 August 1983)

Departments of Medicine and Human Pathology, Kenyatta National Hospital, PO Box 30588, Nairobi, Kenya

KEVIN M DECOCK, MRCP, DTM\&H, lecturer in medicine

S B LUCAS, MRCP, MRCPATH, senior lecturer in human pathology

P H REES, OBE, FRCP, senior lecturer in medicine

Serology Section, Division of Microbiology, State Health Laboratory Services, QE II Medical Centre, Nedlands, West Australia, Australia 6009

A N HODGEN, BAPPSC, technologist in charge

Department of Chemical Pathology, St Thomas's Hospital, London SE1 7EH

R A JUPP, BSC, MSC, senior biochemist

B SLAVIN, MB, MPCPATH, senior lecturer in chemical pathology

Correspondence to: Dr K M DeCock, University of Southern California Liver Unit, Rancho Los Amigos Hospital, Downey, California 90242, USA.

\section{Pericardiocentesis in myocarditis: the protective role of the pericardium in severe heart failure}

The development of tamponade in patients with pericardial effusion is an indication for urgent pericardiocentesis. This decompresses the heart and is potentially life saving. We describe an unusual case of massive pericardial effusion with tamponade complicating myocarditis. Pericardiocentesis was undertaken but led to rapid cardiac dilatation that was ultimately fatal.

\section{Case report}

A previously healthy 23 year old woman presented with dyspnoea on exertion and central chest discomfort. The symptoms had started during a brief influenza like illness 10 weeks previously and had gradually worsened. She had not, however, required time off from her secretarial job before admission.

On examination she was tachypnoeic but not otherwise distressed. The pulse rate was 100 beats/minute with $35 \mathrm{~mm} \mathrm{Hg}$ of paradox. Blood pressure was $160 / 90 \mathrm{~mm} \mathrm{Hg}$. The jugular venous pulse was raised to the angle of the jaw so that evaluation of the wave form and of Kussmaul's sign was not possible. Heart sounds were faint. Chest radiography showed an enlarged globular cardiac silhouette and clear lung fields. An electrocardiogram showed sinus rhythm and low voltage complexes. Echocardiography confirmed the presence of a massive pericardial effusion (figure). The dimensions of the ventricular cavity, however, were normal, and the motion of the walls appeared vigorous. The results of routine blood tests were normal, and virological screening yielded negative results.

Pericardial aspiration by the subxiphisternal route yielded $1900 \mathrm{ml}$ bloodstained serous exudate. Thirty minutes after the pericardiocentesis the jugular venous pulse remained raised and blood pressure had fallen to $105 / 60 \mathrm{~mm} \mathrm{Hg}$. Echocardiography showed successful pericardial aspiration but that considerable cardiac dilatation had occurred. The interventricular septum moved paradoxically, and the free wall of the left ventricle was hypokinetic.

During the next 12 hours cardiogenic shock developed. Right heart catheterisation showed mean right atrial and pulmonary capillary wedge pressures of 11 and $15 \mathrm{~mm} \mathrm{Hg}$ respectively. The radial artery pressure was $69 / 40 \mathrm{~mm} \mathrm{Hg}$. An echocardiogram showed further dilatation of the four chambers and contractile failure. Despite full resuscitative measures she died 22 hours after admission.

Postmortem examination showed pericardial inflammation and a flabby, dilated heart with ventricular scarring and mural thrombosis. Microscopy of the pericardium and myocardium showed widespread inflammatory changes with round cell infiltration and patchy myocyte necrosis. Specimens sent for microbiological examination failed to yield evidence of a specific infective agent.

\section{Comment}

Massive pericardial effusion is rare in myocarditis, and the findings in this case were strongly suggestive of early cardiac tamponade. Though the pericardiocentesis was uncomplicated, it unmasked the underlying myocardial impairment: a paradoxical lowering of blood pressure occurred without correction of the jugular venous pressure. Thereafter progressive cardiac dilatation was associated with worsening ventricular function, a vicious circle described by the "descending limb" of the Starling curve."

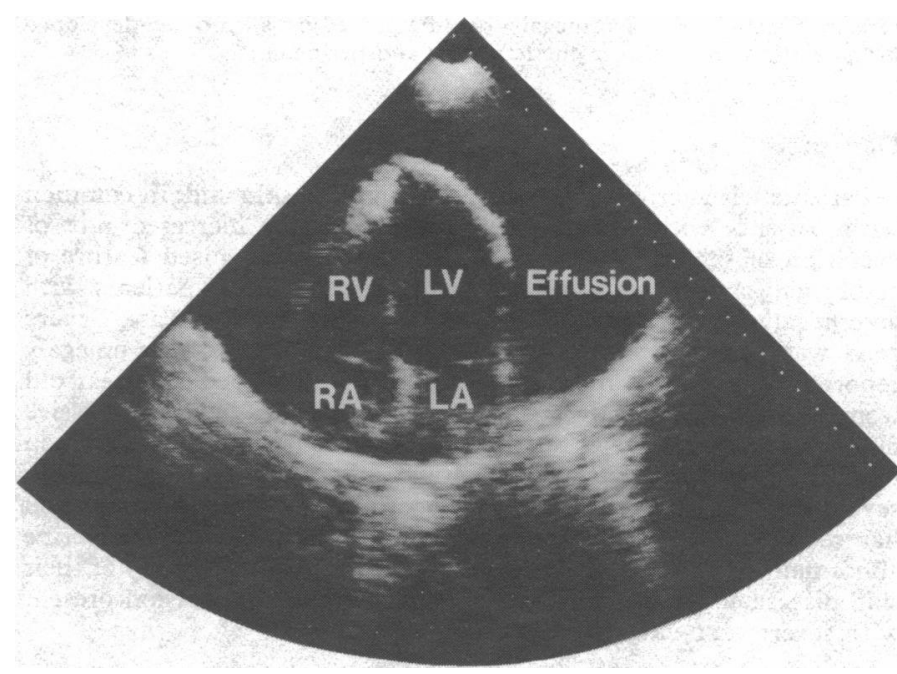

Two dimensional echocardiogram at end diastole showing large pericardial effusion (calculated volume 21 ) surrounding small heart. Dimensions of the left and right ventricular cavities are 3.2 and $2.2 \mathrm{~cm}$ respectively. Dots on the right indicate a centimetre scale.

$L V=$ Left ventricle. $R V=$ Right ventricle. $L A=$ Left atrium. $R A=R i g h t$ atrium.

Experimental studies have shown that the pericardium plays an important part in preventing cardiac dilatation particularly when ventricular end diastolic pressures are raised. ${ }^{23}$ The chronic effusion in this case, however, had clearly stretched the pericardium considerably, rendering it overly compliant and unable to restrain the heart on relief of the tamponade. The diseased myocardium, therefore, was unprotected against the consequences of uncontrolled dilatation.

This physiological explanation best accounts for the rapid worsening of the patient's condition after the pericardiocentesis. Trauma to the heart, kinking of the great vessels, and volume depletion are other potential causes of haemodynamic deterioration in such patients, but the clinical and postmortem examination findings provided no evidence of these complications.

This report emphasises the important constraining influence of an intact pericardium on the failing heart. In this unusual case cardiac tamponade had compensated for the pericardial dysfunction by effectively splinting the myocarditic heart. Gradual drainage of the effusion over several days might have permitted some recovery of normal pericardial compliance and prevented irrecoverable cardiac decompensation.

1 Katz AM. The descending limb of the Starling curve and the failing heart. Circulation 1965;32:871-5.

${ }^{2}$ Berglund E, Sarnoff SJ, Isaacs JP. Ventricular function-role of the pericardium in regulation of cardiovascular hemodynamics. Circ Res $1955 ; 3$ :133-9.

${ }^{3}$ Prindle KH, Gold HK, Beiser GD, Marcus ML, Epstein SE. Influence of pericardiectomy on cat right ventricular function after pulmonary arterial constriction. Am $\mathcal{f}$ Cardiol 1973;31:260-4.

(Accepted 4 August 1983)

Department of Cardiology, King's College Hospital, London SE5 9RS ADAM D TIMMIS, MD, MRCP, research fellow and honorary senior registrar KIERAN DALY, MB, MRCPI, senior registrar

MARK MONAGHAN, MSC, senior chief technician

DAVID E JEWITT, BSC, FRCP, director

Correspondence to: Dr A D Timmis. 